\title{
Genetic diversity in the Lusitano horse breed assessed by pedigree analysis
}

\author{
A.A. Vicente ${ }^{\mathrm{a}, \mathrm{b}, \mathrm{c}}$, N. Carolino ${ }^{\mathrm{a}, \mathrm{d}}$, L.T. Gama ${ }^{\mathrm{a}, \mathrm{c}, *}$ \\ a Unidade de Recursos Genéticos, Reprodução e Melhoramento Animal_INRB, IP 2005-048 Vale de Santarém, Portugal \\ ${ }^{\mathrm{b}}$ Escola Superior Agrária do Instituto Politécnico de Santarém, Apartado 310, 2001-904 Santarém, Portugal \\ c CIISA, Faculdade de Medicina Veterinária-Universidade Técnica de Lisboa, 1300-477 Lisboa, Portugal \\ d Escola Universitária Vasco da Gama, Estrada da Conraria, 3040-714 Coimbra, Portugal
}

\section{A R T I C L E I N F O}

\section{Article history:}

Received 24 November 2011

Received in revised form

13 April 2012

Accepted 2 May 2012

\section{Keywords:}

Genetic diversity

Horse

Inbreeding

Lusitano

Pedigree analysis

Population structure

\begin{abstract}
A B S T R A C T
Genetic diversity and population structure were analyzed in the Lusitano horse breed based on pedigree information of animals registered in the Studbook, to identify factors which may have affected the genetic variability of the breed, and provide the bases for the establishment of sustainable utilization programs. Pedigree records collected from 1824 to 2009 , including information on 53,411 animals, were used in the analyses. The mean generation interval was $11.33 \pm 5.23$ and $9.71 \pm 4.48$ years for sires and dams, respectively, while the mean number of offspring registered was $13.13 \pm 22.53$ for stallions and $4.00 \pm 3.38$ for mares. All great-grandparents were known for the animals in the reference population (registered foals born from 2005 to 2009, $n=9712$ ), which had a mean number of equivalent generations known of $11.20 \pm 0.71$ and an average inbreeding of $11.34 \pm 7.48 \%$. For this population, the rate of inbreeding per year was $0.173 \pm 0.070$, and the effective population size computed from this rate was about 28 . The mean relationship among animals from the same and from different studs was $0.31 \pm 0.16$ and $0.15 \pm 0.10$, respectively. In spite of the high within-stud relationship, inbreeding has been kept lower than expected due to restrictions imposed by breeders on selection and allocation of mates. The effective number of founders, ancestors and studs contributing to the current genetic pool was 27.5, 11.7 and 5.4, respectively. Over the last 30 years, contributions to the genetic pool of Lusitano have been decreasing, with a reduction to about one-half in the effective number of founders and ancestors. Of the 267 founder sires, only 9 Y-chromosome sources are currently represented, with an effective number of 2.23. The diversity of mt-DNA sources is broader, with 129 lineages represented and an effective number of 42.8. The results of our study reflect the intensive emphasis that has been placed on a few sire-families over the years, and raise concerns regarding the conservation of genetic diversity for the future. Methods designed to minimize inbreeding and maximize the maintenance of genetic contributions from different founders and ancestors should be envisaged, to prevent further losses of genetic variability in the Lusitano horse breed.
\end{abstract}

(c) 2012 Elsevier B.V. All rights reserved.

\footnotetext{
* Corresponding author at: CIISA, Faculdade de Medicina VeterináriaUniversidade Técnica de Lisboa, 1300-477 Lisboa, Portugal.

Tel.: +351 213652800; fax: +351 213652889 .

E-mail address: Itgama@fmv.utl.pt (L.T. Gama).
}

\section{Introduction}

Horses have a long history in the Iberian Peninsula. The Lusitano horse is the most important native equine breed in Portugal, and it has contributed to the development of horse breeds in other parts of the world, 
especially in the American continent (Luis et al., 2007b). Currently, there are approximately 5000 Lusitano registered breeding mares, of which about one-half are kept in Portugal and the remaining animals are spread throughout the world (Vicente et al., 2009). For many years, the Lusitano and the Pura Raza Española from Spain were jointly designated as Andalusian, Iberian or Peninsular horses, until the official Studbook of the Lusitano was established in 1967 (APSL, 2010). However, these two Iberian horse populations had already been selected with different objectives for several centuries, i.e., the Pura Raza Española horses were selected mostly for beauty, conformation and gaits, while Lusitano horses continued to be selected based on functional aspects, including their use in bullfighting and herd management (Bowling and Ruvinsky, 2000; Loch, 1986). In recent years, both breeds have established breeding programs, aimed at the genetic improvement of their horse populations (APSL, 2010; MAPA, 2003).

Different constraints have threatened the survival of the Lusitano horse through the years, especially in the 19th and 20th centuries. These included wars and foreign invasions in the 19th century, the mechanization of agriculture in the first half of the 20th century, political turmoils in several occasions, uncontrolled crossbreeding with other breeds, etc., which probably represented bottlenecks that may have caused a reduction in the Lusitano gene pool over time. As a consequence, despite the long tradition of Lusitano horses in Portugal for several centuries, in the period when the Studbook was established after 1967 the number of remaining animals was rather small, and the current population is considered to have derived from a reduced number of founder animals (Lopes et al., 2005). Moreover, it is not clear if pedigree constraints occurred afterwards may have resulted in further genetic erosion.

The analyses of inbreeding and relationships, and their changes over time, have often been used to monitor the evolution of genetic diversity in a population (Falconer and MacKay, 1996; Hill, 2000). In addition, parameters based on the probability of genetic origin from different herds (Robertson, 1953), founders (James, 1972; Lacy, 1989), and ancestors (Boichard et al., 1997) have also been used, to assess changes occurred in the population over a short period of time (Boichard et al., 1997). These principles have been applied to the genetic characterization of different horse breeds, including the Asturcon (Royo et al., 2007), Austrian Noriker (Druml et al., 2009), Franches-Montagnes (Poncet et al., 2006), French race and riding horse breeds (Moureaux et al., 1996), Hanoverian Warmblood (Hamann and Distl, 2008), Lipizzan (Zechner et al., 2002), Mangalarga Marchador (Costa et al. 2005), Mangalarga (Mota et al., 2006), Pura Raza Española (Valera et al., 2005), Quarter Horse (Tunnell et al., 1983), Spanish Arab (Cervantes et al., 2008), Standardbred (MacCluer et al., 1983), Thoroughbred (Cunningham et al., 2001) and Trakehner (Teegen et al., 2009).

The objectives of this study were to monitor past and current trends in the genetic structure of the Lusitano horse breed based on pedigree analysis, and identify factors which may have affected the genetic variability of the breed, thus providing the bases for the establishment of sustainable utilization programs designed to minimize further losses of genetic diversity.

\section{Materials and methods}

\subsection{Animals}

The information used in this study was obtained from the data files of the Fundação Alter Real (FAR—National Stud) and from the Portuguese Lusitano Horse Breeders Association (APSL).

There are nearly 5000 active Lusitano breeding mares registered in the Studbook, spread by about 600 studs (APSL, personal communication, 2010). The vast majority of these females are raised under extensive conditions, and breeding occurs mostly by natural mating. Until 1997 , artificial insemination was not allowed by Studbook regulations, but since then it has been progressively used on a limited scale (APSL, 2010).

The Lusitano Studbook was officially established in 1967, but pedigree records were kept since the mid-19th century by private producers and the National Stud. Until 1989, the Studbook allowed the registration of offspring from unregistered animals, as long as they corresponded to the breed standard, as decided by a jury of experts. After 1989, only offspring of registered stallions and mares could be registered, and since 1992 Studbook regulations require that systematic parentage testing must be carried out before an animal can be registered. Parentage confirmation was first carried out by blood groups, and since 1998 with microsatellite markers.

\subsection{Data}

Pedigree records were completed and validated with data provided by APSL, to include information collected throughout the world. Data were checked and validated for consistency of dates, individual identification, duplicates, etc. After editing, the data file included pedigree records of 53,411 horses, born from 1824 to 2009 .

The genetic contributions of founders, ancestors, founding studs and founder genomes were studied, by considering a reference population which was defined as the group of foals $(n=9712)$ registered in the Studbook with birth year from 2005 to 2009 .

\subsection{Pedigree analysis}

Demographic analyses were performed with software specifically developed for this purpose (Carolino and Gama, 2008) and, where indicated, with the ENDOG v4.8 software (Gutierrez and Goyache, 2005).

The equivalent number of complete generations known per animal $\left(n_{i}\right)$ was used to assess the degree of pedigree completeness, and calculated as

$n_{i}=\frac{n_{s}+n_{d}}{2}+1$,

where $n_{s}$ and $n_{d}$ are the number of generations known for the sire and dam, respectively, when $s$ and $d$ are known; if 
$s$ or $d$ are unknown, then $n_{s}$ or $n_{d}$, respectively, assume a value of -1 . Base animals were assigned a number of generations known equal to 0 .

Generation intervals were computed for the sires and dams of all foals born, and for the 4 paths of selection (average age of sires of stallions, sires of mares, dams of stallions and dams of mares). The latter were averaged to obtain a pooled generation interval $(L)$.

Individual coefficients of inbreeding $\left(F_{x}\right)$ and additive genetic relationships among pairs of animals were computed based on the numerator relationship matrix among all animals (Van Vleck, 1993), with software developed by Carolino and Gama (2008).

The degree of non-random mating practiced by breeders was assessed by comparing the inbreeding achieved and the relationship among sires and dams in a sample of 146 studs producing more than one foal per year in the period 2005-2009. In these studs, the mean inbreeding of foals born in a given year was compared with the average relationship among all sires and dams active in the same stud one year earlier, and these were averaged for the five years in study.

The regression coefficient of individual inbreeding on year of birth was obtained with the GLM procedure of SAS (SAS Institute, 2004), and this was considered to be the rate of inbreeding per year $(\Delta F /$ year). The rate of inbreeding per generation $(\Delta F / g)$ was then computed as $\Delta F / g=L$ $\left(\Delta F /\right.$ year) and effective population size $\left(N_{\mathrm{e}}\right)$ was calculated as $N_{\mathrm{e}}=1 / 2(\Delta F / g)$. In addition, $N_{\mathrm{e}}$ was also calculated based on the individual increase in inbreeding, as suggested by Gutierrez et al. (2009).

The genetic contributions to the reference population of founder animals, ancestors and founding studs were computed, as described by James (1972), Lacy (1989) and Boichard et al. (1997). The effective number of founders $\left(f_{\mathrm{e}}\right)$, ancestors $\left(f_{\mathrm{a}}\right)$ and studs $\left(f_{\mathrm{s}}\right)$ were computed from those genetic contributions as

$f_{j}=\frac{1}{\sum_{k=1}^{n} q_{k}^{2}}$

where subscript $j$ corresponds to founders, ancestors or studs, depending on the situation considered, and $q_{k}$ represents the genetic contribution of a given founder or founding stud, or the marginal contribution of an ancestor (Boichard et al., 1997).

The effective number of founder genomes $\left(f_{\mathrm{g}}\right)$ was computed with ENDOG (Gutierrez and Goyache, 2005), to take into account the unequal contributions of founders and the possible random loss of alleles throughout successive generations due to genetic drift (Lacy, 1989). This software was also used to calculate average relatedness (AR), which corresponds to the mean relationship of each individual with all animals in the pedigree.

A genetic conservation index (GCI), as proposed by Alderson (1992), was computed for each individual, with ENDOG (Gutierrez and Goyache, 2005). The GCI is calculated individually in a manner similar to $f_{\mathrm{e}}$, and can be used to maximize the retention of genetic contributions from the different founders, with higher index values corresponding to individuals with a more balanced representation from a large number of founders. The evolution of GCI over time was assessed by obtaining the regression coefficient of the GCI per animal on year of birth, using the GLM procedure of SAS (SAS Institute, 2004).

The genetic contributions of different studs supplying sires, paternal grandsires and great-grandsires to the reference population were evaluated according to Robertson (1953), and computed with ENDOG (Gutierrez and Goyache, 2005).

The transmission of Y-chromosomes along the male path from founder stallions to the male foals in the reference population was analyzed. From the proportion of founder Y-chromosomes currently represented, an effective number of $Y$ founders was calculated, using the same principles defined for the effective number of founders. Similar criteria were used to assess the transmission of mitochondrial DNA (mt-DNA) along the dam path, from founding mares to the foals in the reference population (Carolino and Gama, 2008).

\section{Results}

The number of animals registered in the Studbook between 1967 and 2008 (Fig. 1) has shown a steady increase in the number of foals registered up to 2004 , especially after 1982 . In recent years, the number of studs with foals registered was about 700 , producing an average of $2.18 \pm 3.00$ foals per stud in the period 2005-2008, of which only 303 studs had more than 2 foals registered. Annually, the mean number of stallions and mares registered in the Studbook is about 100 and 300, respectively, with a cumulative number of 4562 stallions and 11,902 mares registered since the creation of the Studbook in 1967 until 2008.

The age distribution of sires and dams of registered foals (Fig. 2) indicates that, on average, mares had their first foal at $5.44 \pm 2.04$ years of age, while stallions are $7.30 \pm 3.62$ years old when their first product was born. Overall, the mean age of parents was $11.33 \pm 5.23$ years for sires and $9.71 \pm 4.48$ years for dams, indicating a long use in reproduction of both males and females, even though mares are kept active for a shorter period than stallions. As a result, the proportion of total offspring produced by sires and dams after 10 years of age was $51 \%$ for stallions and $40 \%$ for mares, and nearly $10 \%$ of the foals born are the offspring of stallions after 19 years of age.

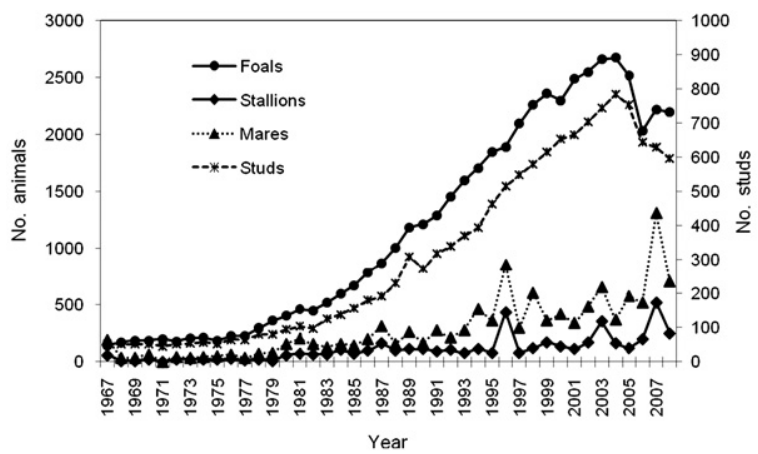

Fig. 1. Number of foals, stallions and mares registered in the Lusitano Studbook by year, and corresponding number of studs represented. 
The long use of sires in reproduction could delay the benefits of the selection program, and would provide the opportunity for matings among close relatives, if no provisions are taken. Nevertheless, the number of parent-offspring matings in Lusitano is not too high (less than $2 \%$ ), which probably reflects the concern that breeders have in avoiding those close matings.

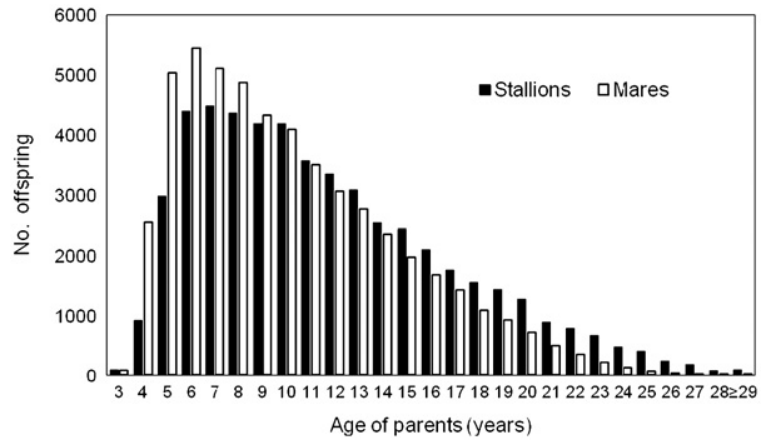

Fig. 2. Age distribution of stallions and mares producing foals in the Lusitano population.

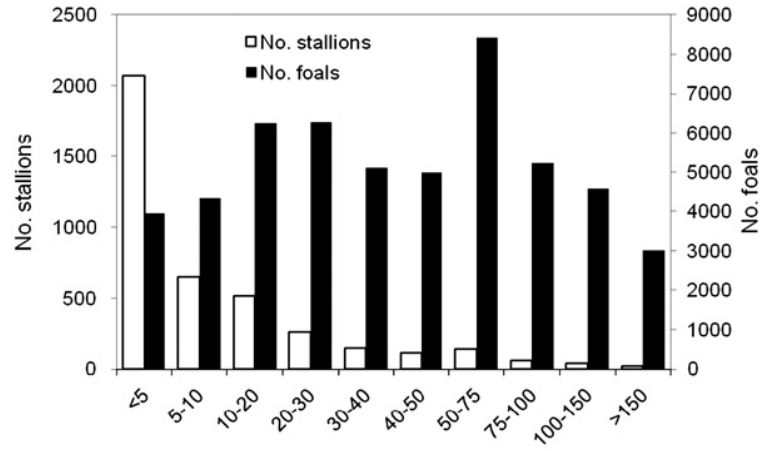

No. of foals born per stallion

Fig. 3. Number of stallions and foals, by classes of number of foals per stallion for the Lusitano population.
The overall mean generation interval based on the age of dams and sires used in the Lusitano population was 10.52 years, and it was lower in mares by about 1.6 years. When the four paths of selection were considered (sires of stallions, dams of stallions, sires of mares and dams of mares), the mean generation interval was 10.28 years and, on average, parents of stallions were 1.2 years older than parents of mares. On the other hand, the age of sires of selected stallions and mares was about 0.5 years lower than that calculated when all sires were considered. The variability among animals in generation interval was quite large, with a coefficient of variation ranging from about $46 \%$ to $50 \%$ for the different paths of selection.

The mean number of foals registered per dam was $4.00 \pm 3.38$ and the corresponding figure for sires was $13.13 \pm 22.53$. The number of offspring produced per stallion (Fig. 3) indicates that about $52 \%$ of the stallions have less than 5 offspring registered, and only $10 \%$ have more than 40 offspring. Nevertheless, about $50 \%$ of the total number of foals born are produced by stallions siring more than 40 foals, with the highest number observed for one sire with 224 registered offspring.

Pedigree records were available from 1824 until 2009, such that the average percentage of known parents, grandparents and great-grandparents in the full data set $(n=53,411)$ was $98.78 \%, 97.80 \%$ and $97.08 \%$, respectively, while for animals in the reference population (foals born from 2005 to 2009) all those ancestors were known (results not shown).

The number of equivalent generations known per animal has increased steadily over the years, to reach a mean of $11.20 \pm 0.71$ generations known for animals in the reference population and $9.87 \pm 2.04$ generations for the full data set (Table 1).

Average inbreeding was $9.92 \%$ for all registered animals and $11.34 \%$ for the reference population (Table 1 ). Mean inbreeding per year of birth in the Lusitano population (Fig. 4) remained nearly stable up until 1995, and increased steadily afterwards, to reach a mean inbreeding coefficient of $11.64 \%$ for animals born in 2008 . Presently, all animals born in the reference population have $F_{x} \neq 0$,

Table 1

Inbreeding and relationships coefficients $( \pm S D)$ in the Lusitano horse breed for all animals and for the reference population (foals born from 2005 to 2009).

\begin{tabular}{|c|c|c|}
\hline Item & All animals ( $n=53,411)$ & Reference population ( $n=9712)$ \\
\hline No. of generations known & $9.87 \pm 2.04$ & $11.20 \pm 0.71$ \\
\hline Average inbreeding coefficient (\%) & $9.92 \pm 8.34$ & $11.34 \pm 7.48$ \\
\hline Animals with inbreeding coefficient $\neq 0(\%)$ & 96.62 & 100.00 \\
\hline$\Delta F /$ year $(\%)^{\mathrm{a}}$ & $0.0084 \pm 0.0004$ & $0.1728 \pm 0.0701$ \\
\hline$\Delta F /$ generation (\%) & 0.09 & 1.78 \\
\hline Effective population size ${ }^{\mathrm{b}}$ & 576.70 & 28.15 \\
\hline Effective population size $\mathrm{c}^{\mathrm{C}}$ & & 41.24 \\
\hline Average relatedness & $0.1164 \pm 0.0444$ & $0.1354 \pm 0.0312$ \\
\hline Genetic conservation index & $9.32 \pm 2.73$ & $9.53 \pm 2.20$ \\
\hline Mean relationship among animals from the same stud & & $0.3128 \pm 0.1586$ \\
\hline Mean relationship among animals in different studs & & $0.1456 \pm 0.0983$ \\
\hline
\end{tabular}

a $\Delta F=$ the rate of inbreeding.

${ }^{\mathrm{b}}$ According to Falconer and MacKay (1996).

${ }^{\text {c }}$ According to Gutierrez et al. (2009). 


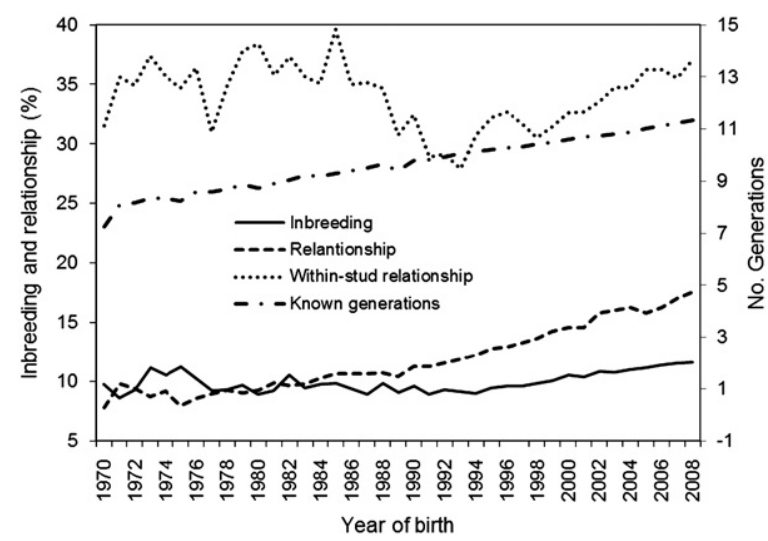

Fig. 4. Means (\%) by year of birth for inbreeding coefficient, relationship for all animals and animals born in the same stud and for number of generations known in the Lusitano horse breed.

and only about $3 \%$ of the animals in the full data set are not inbred (Table 1 ).

The $\Delta F /$ year was $0.1728 \pm 0.0701 \%$ for the reference population and $0.0084 \pm 0.0004 \%$ when the whole population was considered. The $\Delta F / g$ (computed from the $\Delta F /$ year assuming a mean generation interval of 10.28) and the corresponding $N_{\mathrm{e}}$ were $0.09 \%$ and 576.70 , respectively, for the full data and $1.78 \%$ and 28.15 for the reference population (Table 1 ). When $N_{\mathrm{e}}$ was calculated based on the individual increase in inbreeding (Gutierrez et al., 2009), the corresponding estimate was 41.24 . When animals born from 1970 to 2008 were considered, the $\Delta F / g$ and $N_{\mathrm{e}}$ were $0.75 \%$ and 66.5 , respectively, but these figures changed to $1.59 \%$ and 31.0 in animals born from 2000 to 2008 (results not shown).

The average relatedness calculated for animals in the reference population (Table 1 ) was about 0.135 , while the mean relationship among animals in the same stud was about twice that observed for animals in different studs (about 0.31 vs. 0.14 ). The year means for the relationship between all animals and those born in the same stud (Fig. 4) indicate that, until the Studbook was closed in 1989, the mean within-stud relationship per year of birth oscillated between $29 \%$ and $38 \%$, but since then it is increasing every year (from $30 \%$ to $37 \%$ ). On the other hand, the mean relationship of all animals born in the same year has shown a steady increase from about $8 \%$ in 1970 to $18 \%$ in 2008.

The degree of non-random mating practiced by breeders was assessed by studying the association between the relationship among active sires and dams and the observed inbreeding per stud (Fig. 5). Nearly $80 \%$ of the studs fall below the diagonal representing the expected inbreeding for a given relationship, and thus have a lower than expected degree of inbreeding, reflecting the concern of breeders in avoiding matings among closely related individuals. Nonetheless, $0.31 \%, 4.65 \%$ and $1.84 \%$ of the matings in the whole population were among full-sibs, half-sibs and parent-offspring, respectively (results not shown).

The 53,411 Lusitano horses registered up until 2009 result from genetic contributions of 796 founders (267

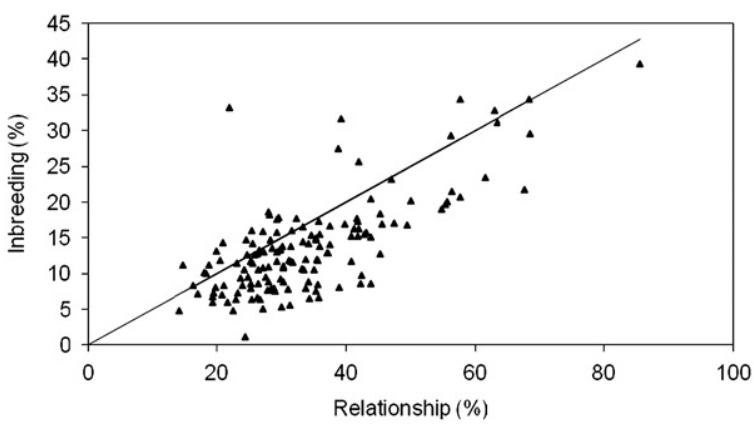

Fig. 5. Association between mean inbreeding coefficient by stud, for Lusitano foals born in 2005 to 2009, and average relationship between active stallions and mares in the same studs, with solid line representing the expected inbreeding for a given relationship.

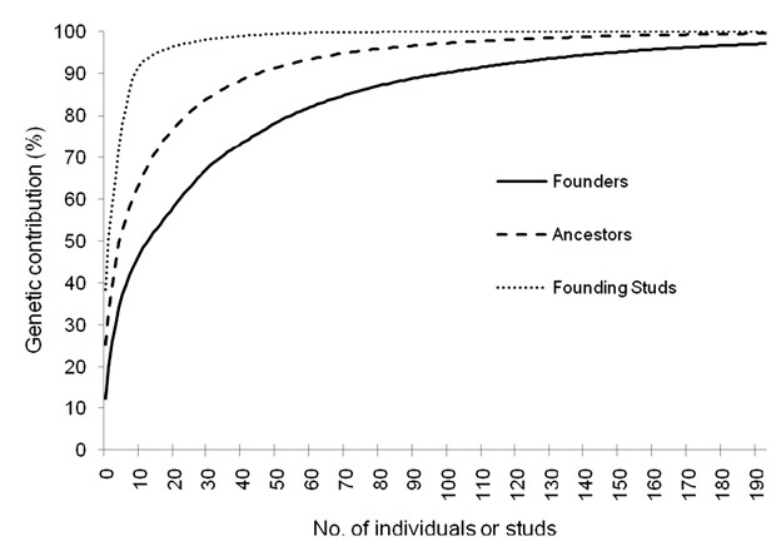

Fig. 6. Cumulative genetic contribution to the reference population (Lusitano foals born from 2005 to $2009, n=9712$ ) of the most influential founders, ancestors and founding studs.

sires and 529 mares) from 110 founding studs, with 17,487 ancestors registered for the whole population. The cumulative genetic contributions of founders, ancestors and studs to the genetic pool of the reference population is shown in Fig. 6, which clearly indicates a very strong influence of a few ancestors and founding studs to the Lusitano horse breed. Indeed, $50 \%$ of the genetic pool of the breed is justified by genetic contributions from 14 founders, six ancestors and two founding studs, with the two most influential founders, ancestors and founding studs contributing with nearly $20 \%, 33 \%$ and $51 \%$ of the genetic pool, respectively (Table 2 ). The highly unbalanced share of the different contributors to the genetic pool of the reference population resulted in an effective number of founders, ancestors and founding studs of about 28, 12 and 5, respectively. Evidence of a strong influence of a few studs on the genetic pool of Lusitano horses is also supported by the effective number of studs supplying sires, grandsires and great-grandsires to the reference population, which was about 32, 10 and 8 , respectively. Overall, the effective number of founder genomes, which takes into account the possible loss of alleles from the founders to the current generation, was about 6 (Table 2). 
Table 2

Genetic contributions of founders, ancestors and founding studs to the reference population (foals born between 2005 and 2009, $n=9712$ ) in the Lusitano horse breed.

\begin{tabular}{ll}
\hline Item & \\
\hline Effective number & \\
Founders $\left(f_{\mathrm{e}}\right)$ & 27.47 \\
Ancestors $\left(f_{\mathrm{a}}\right)$ & 11.73 \\
Founding studs & 5.40 \\
Studs supplying sires & 32.14 \\
Studs supplying grandsires & 9.94 \\
Studs supplying great-grandsires & 7.57 \\
Founder genomes & 6.01 \\
Ratio $f_{\mathrm{e}} / f_{\mathrm{a}}$ & 2.34 \\
Contribution to $50 \%$ of the genetic pool & \\
Founders & 14 \\
Ancestors & 6 \\
Founding studs & 2 \\
Contribution to $90 \%$ of the genetic pool & 99 \\
Founders & 46 \\
Ancestors & 10 \\
Founding studs & 19.88 \\
Contribution of 2 most influential founders (\%) & 32.97 \\
Contribution of 2 most influential ancestors $(\%)$ & 50.72 \\
Contribution of 2 most influential founding studs (\%) & \\
&
\end{tabular}

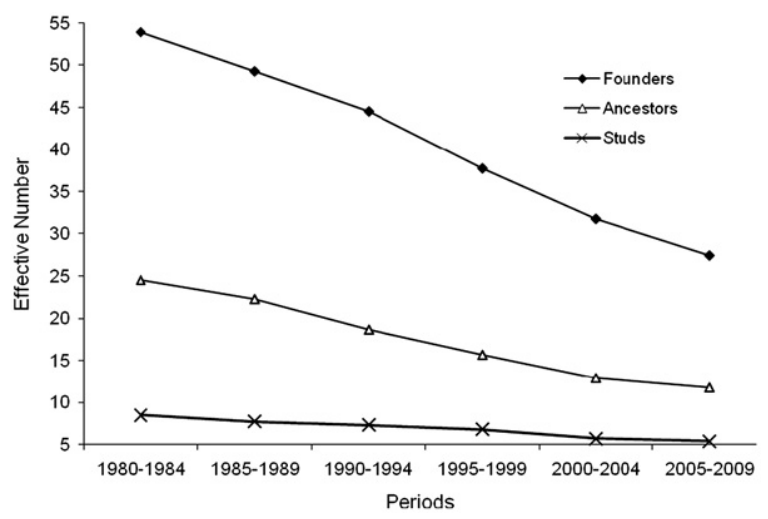

Fig. 7. Evolution of effective number of founders, ancestors and founding studs to Lusitano foals born over the last 30 years, considering reference populations in successive periods of 5 years.

The progressive reduction in genetic variability occurred in the Lusitano population over the last few years is further confirmed by the decline in the effective number of founders, ancestors and founding studs contributing to the genetic pool of the population (Fig. 7). In the period between 1980 and 1984, and 2005 and 2009, the effective number of founders and ancestors represented in the population dropped by about $50 \%$, and that of effective studs dropped by nearly $37 \%$. Also, the number of founders and ancestors contributing to $50 \%$ of the genetic pool in 2005-2009 was only two-thirds of that observed in the period 1980-1984 (results not shown).

This trend in the reduction of founder and ancestor contributions was largely due to the heavy use of some popular sire-lines, which have been progressively more represented in the Lusitano genetic pool (Fig. 8).

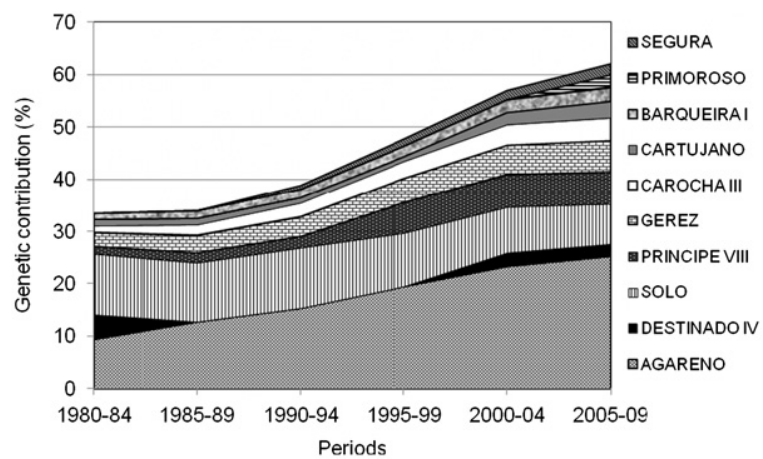

Fig. 8. Evolution of marginal genetic contributions of the 10 major ancestors to Lusitano foals born over the last 30 years, in periods of 5 years.

For example, the predominant ancestor of the breed (Agareno), which was born in 1931, had a contribution corresponding to about $10 \%$ of the genetic pool in the period 1980-1984 and nearly 25\% in 2005-2009. Furthermore, the 10 more influential ancestors in the current Lusitano genetic pool increased their contribution from $37 \%$ in $1980-1984$ to $62 \%$ in $2005-2009$.

Of the 267 founder sires, only nine have contributed Y-chromosomes to the current population, and two sires have contributed $94.5 \%$ of the existing Y-chromosome sources. Following the same principles, of the 529 founder mares, there are only 129 with mt-DNA represented in the current population. The mare with the highest representation has contributed $7 \%$ of the current mt-DNA sources, and 16 founder maternal lineages justify $50 \%$ of the mt-DNA diversity. Overall, the effective number of Y-chromosome founders was 2.23 and that of mt-DNA founders was 42.8 .

The number of founders represented in the contributions received by an individual, and the balance among them, was assessed by calculating the GCI of all animals. It is assumed in this case that higher GCI values correspond to animals with a more balanced representation from a large number of founders. For the reference population, the GCI had a global mean of about 9.5 (Table 1 ), and ranged from 4.59 to 19.24 . Over time, a reduction has been observed in the global GCI of the population, with a regression coefficient on year of birth of $-0.00974 \pm$ $0.00150(P<0.0001$, results not shown $)$ for animals born from 1980 to 2009 .

\section{Discussion}

The Lusitano has a very long history, with pedigree information dating back to the beginning of the 19th century, with more than 11 generations known on average for registered animals born between 2005 and 2009. This provides a very comprehensive amount of information to study the evolution of genetic diversity and of factors affecting it in this breed.

The number of registered animals in the Lusitano Studbook increased steadily after the 1980s, mostly because of the popularity of the breed as leisure horse and its success in various equestrian disciplines (e.g. 
carriage, dressage, working equitation, etc.). Currently, the Lusitano has a registered population of about 5000 breeding mares and 1000 stallions, which is comparable to the Lipizzan breed, with close to 3000 mares (Curik et al., 2003), but is much smaller than the number registered for other breeds, including the Hanoverian with 19,000 females (Hamann and Distl, 2008), the Pura Raza Española with about 60,000 (Azor, 2009) and the Thoroughbred horse with over 100,000 registered mares (Ricard et al., 2000). The existing Lusitano population is mostly the progeny of about 100 animals which were registered in the mid-1950s, as only 11 additional founders entered the population after this time, while the Studbook was open to new registrations up until 1989. The breed has, therefore, developed from a very narrow base, with a heavy influence of a reduced number of popular studs and stallions, which should have caused an unavoidable reduction in genetic diversity.

The age distribution in Lusitano indicates that the first offspring are usually born when mares are, on average, 5.5 years old, and sires nearly 2 years older. This is largely because, to be registered as breeding stock, both sires and dams have to be submitted to a morpho-functional test, which in the case of sires requires that they are ridden by a horseman, and scored on gaits and conformation. Mares, on the other side, are scored when they are presented by hand to a jury of experts. This implies that horses must be trained before their registration in the Studbook, and this has obvious consequences in delaying the initiation of their reproductive career. Also, sires often enter reproduction after being used for several years in equestrian activities, while mares are frequently used only for breeding. As a consequence, the age distribution results in a mean age of breeding stallions higher by about 1.5 years when compared to mares, because sires initiate and finish their breeding function later than mares.

Overall, the generation interval in Lusitano is rather long, with a global mean for the four paths of selection of about 10.3 years. Nevertheless, this is in line with the mean generation intervals reported for other saddle horse breeds, including the Pura Raza Española (10.1 years, Valera et al., 2005), Mangalarga (9.49 years, Mota et al., 2006), Hanoverian (10 years, Hamann and Distl, 2008), Arab-derived horses in Spain (10.1-12.0 years, Cervantes et al., 2009), Trakehner (10.2 years, Teegen et al., 2009) and French saddle horses (9.7-11.8, Moureaux et al., 1996), but higher than in draught horse breeds such as the Austrian Noriker (7.9 years, Druml et al., 2009) and the Franches-Montagnes ( 8.3 years, Poncet et al., 2006).

Traditionally, modifications in genetic variability of a population have been assessed by evaluating the degree of inbreeding and its changes over time (Falconer and MacKay, 1996; Hill, 2000), and programs aimed at maximizing the retention of genetic diversity usually recommend the minimization of the rate of inbreeding (Caballero and Toro, 2000). For example, it has been recommended that the effective size of a population should exceed a minimum of 50 , to maintain genetic diversity at an acceptable level both in conservation (FAO, 1998; Meuwissen and Woolliams, 1994) and in selection programs (Goddard and Smith, 1990).
In addition to the control of inbreeding, the assessment of genetic contributions from studs, founders and ancestors to the current population may provide a better understanding of the changes taking place in the genetic pool of a breed, especially when those are considered over a small number of generations (Boichard et al., 1997). When only the number of founders, ancestors and studs contributing to the genetic pool is considered, the possibility of unbalanced contributions among the different founders, ancestors and studs is not taken into account, and the assessment of genetic bottlenecks is thus not possible. Hence, the use of an effective number is often preferred, which in the case of founders corresponds to the equivalent number of founders that would generate the same genetic diversity as that observed in the population studied, if they all had the same contribution. A similar approach is used when interpreting the effective number of founding studs and ancestors, which give further insight into the genetic changes occurred in the population in a short period of time. The relationships between $N_{\mathrm{e}}, f_{\mathrm{e}}$ and $f_{\text {a }}$ provide information on the occurrence of bottlenecks in the population, such that $f_{\mathrm{e}}$ should be close to $N_{\mathrm{e}} / 2$ in a population where genetic drift has stabilized (Caballero and Toro, 2000; Sorensen et al., 2005) and the ratio $f_{\mathrm{e}} / f_{\mathrm{a}}$ should be close to 1 if important bottlenecks have not occurred in the population (Boichard et al., 1997).

In our study, the mean inbreeding in Lusitano horses born in the period $2005-2009$ was $11.34 \%$, which is similar to that observed in Pura Raza Española (Valera et al., 2005), Lipizzan (Zechner et al., 2002) and Thoroughbred horses (Cunningham et al., 2001). Over the last few years, the distribution of animals in different levels of inbreeding has changed in the Lusitano horse breed, such that presently all Lusitano horses have some degree of inbreeding, and there are fewer animals than in the past in the lowest $(<5 \%)$ levels of inbreeding, as a consequence of the progressively higher relationship among breeding animals (Fig. 4). On the other hand, a reduction has also been observed over the years in the highest inbreeding categories ( $>25 \%$ ) reflecting the concern that studs now have in avoiding matings among closely related individuals. As a matter of fact, the majority of the studs have a mean inbreeding of the foals which is lower than would be expected from the mean relationship among their breeding stock, such that, on average, the mean inbreeding was about $18 \%$ lower than it would be if no restraints were used in mate selection and allocation. Nevertheless, a few studs still have extremely high mean relationships among their breeding stock, and do not seem to be making a particular effort to minimize inbreeding in the foals produced. One possible way to keep inbreeding at lower levels in Lusitano is to exchange animals among studs, as the mean relationship between studs is less than one-half that observed within studs. Additionally, the exchange of registered Lusitano horses among countries which have been genetically more isolated could further reduce the mean relationship among breeders, thus lowering the level of inbreeding in the population.

Given the depth of pedigree knowledge, the reduced census of the population and the long use in reproduction of stallions and mares, it could be anticipated that the 
present levels of inbreeding in Lusitano would be higher than actually observed. This discrepancy is a consequence of the very high number of sires used in the Lusitano horse breed, with a sex ratio of nearly 5 mares per stallion, which is much lower than, e.g., the ratio of 45 mares/sire observed in Hanoverian horses (Hamann and Distl, 2008). Due to the high number of stallions used, the mean number of offspring registered per sire is only about 13 , and nearly one-half of the sires have less than 5 offspring registered. Nevertheless, 56 popular stallions have sired nearly $15 \%$ of the foals registered in the breed, with an average of 135 foals/stallion.

The rate of inbreeding per year in Lusitano was relatively low when the full data were considered (less than $0.01 \% /$ year), but it has increased over the last 20 years, to reach $0.17 \% /$ year in the period $2005-2009$. As a result, $N_{\mathrm{e}}$ has dropped to nearly 28 in the Lusitano population over the last five years, which is nearly onehalf of the recommended minimum $N_{\mathrm{e}}$ for maintenance of genetic diversity (FAO, 1998; Meuwissen and Woolliams, 1994) and much lower than the estimates obtained for other horse breeds, including the Franches Montagnes $\left(N_{\mathrm{e}}=62\right.$, Poncet et al., 2006), Lipizzan $\left(N_{\mathrm{e}}=102\right.$, Zechner et al., 2002), Arab derived horses in Spain $\left(N_{\mathrm{e}}=110-135\right.$, Cervantes et al., 2009), Austrian Noriker $\left(N_{\mathrm{e}}=157\right.$, Druml et al., 2009) and Hanoverian $\left(N_{\mathrm{e}}=372\right.$, Hamann and Distl, 2008). Even if we consider the $N_{\mathrm{e}}$ computed from the individual increase in inbreeding in the Lusitano $\left(N_{\mathrm{e}}=41\right)$, it remains below the minimum recommended for maintenance of genetic diversity.

Of the 796 founders which gave origin to the Lusitano horse breed, large differences were observed in their genetic contributions to the current population, with two founders contributing about $20 \%$ of the genetic pool. The effective number of founders, which currently is about 27 , has been declining steadily, dropping by nearly one-half from 1980-1984 to 2005-2009. This result is in contrast to the expectation that relative founder contributions tend to stabilize in closed populations after a short number of generations (Caballero and Toro, 2000; McPhee and Wright, 1925), a pattern which has been observed in Thoroughbred horses (Cunningham et al., 2001). This discrepancy must be a result of the continuing selection practiced in Lusitano horses, where the popularity of a few sires and studs over the last decades has increased enormously their contribution to the genetic pool, and caused the loss of several founder lines. This is confirmed by the analysis of ancestors contributions, with an effective number of about 12 in the reference population, and a decrease in $f_{\mathrm{a}}$ of more than one-half between 1980 and 1984, and 2005-2009. Currently, the predominant ancestor accounts for nearly $25 \%$ of the genetic pool, and the two major ancestors contribute about one-third of the diversity found in Lusitano horses, and are represented in $96 \%$ and $98 \%$, respectively, of the pedigrees of animals in the reference population. Furthermore, the effective number of founding studs has also decreased to 5.4 in 2005-2009, and two studs alone contribute with $50 \%$ of the genetic diversity.

The effective number of founders encountered for Lusitano is much lower than what has been reported for several other horse breeds (Druml et al., 2009; Hamann and Distl, 2008; Valera et al., 2005; Zechner et al., 2002), and only comparable to the results obtained in the Thoroughbred horse (Cunningham et al., 2001). Still, the ratio of $f_{\mathrm{e}}$ relative to the total number of founders is about five times higher for the Thoroughbred, indicating that their more reduced number of founders $(n=158)$ is better represented in the current population than in the case of Lusitano. Also for the contributions of ancestors, the effective number of about 12 calculated for Lusitano is the lowest when compared with those found in the literature for other horse breeds, which range between about 17 and 78 (Cervantes et al., 2008; Druml et al., 2009; Hamann and Distl, 2008; Poncet et al., 2006; Valera et al., 2005; Zechner et al., 2002).

Taken together, our analyses of genetic contributions of founders, ancestors and studs indicate that a serious reduction in genetic diversity is taking place in the Lusitano horse breed, which is still not clearly translated as increased inbreeding, but is very evident from the progressive loss of genetic contributions of founders and ancestors, which has caused an overall reduction in the genetic variability of the breed. This result confirms the usefulness of using the analysis of genetic contributions for the management of genetic diversity, as proposed by Boichard et al. (1997), as it provides information on the occurrence of bottlenecks in the population and the resulting loss in genetic diversity over a short period of time.

The comparison of $N_{\mathrm{e}}, f_{\mathrm{e}}$ and $f_{\mathrm{a}}$ can be used to assess the occurrence of changes in genetic drift and recent bottlenecks in a population, which are corroborated if $\left(f_{\mathrm{e}} / N_{\mathrm{e}}\right)>0.5$ or $\left(f_{\mathrm{e}} / f_{\mathrm{a}}\right)>1$, respectively (Sorensen et al., 2005). In our study, the reference population had a ratio $f_{\mathrm{e}} / N_{\mathrm{e}}$ of about 1.0 , indicating that genetic drift is not stable in the Lusitano horse breed, with progressive loss of founder representation (Caballero and Toro, 2000; Sorensen et al., 2005). This is further confirmed by the effective number of founder genomes of about 6.0, which is nearly one-fifth of the effective number of founders, and reflects the loss of alleles over time due to genetic drift. On the other hand, the ratio $f_{\mathrm{e}} / f_{\mathrm{a}}$ was 2.34 , confirming the occurrence of important bottlenecks in the population, due to the intensive use of a few popular lines. The $\mathrm{GCI}$ calculated for the reference population indicates that an average animal has a mean contribution of about 9.5 founders (assuming that they have a balanced representation), but there is a large variability among individuals in the number and balance of founder representation. The use of the GCI in a breeding program is expected to maximize the retention of the allelic richness present in the base population (Alderson, 1992), but it does not take into account pedigree bottlenecks which may have occurred through non-founder individuals. Notwithstanding, of particular concern is the fact that GCI has been decreasing over time, confirming that founder representation is being progressively lost in the Lusitano.

The reduction observed in the genetic contribution of founders is even more expressive when the transmission of $\mathrm{Y}$ chromosome founder lineages is considered. Currently, there are only $3.4 \%$ of the original Y-chromosome 
sources represented and an effective number of nearly 2 , with two lineages corresponding to about $95 \%$ of those sources in the reference population. For dam lineages, the representation of mt-DNA founder sources is more diversified than for Y chromosomes, with an effective number of mt-DNA lineages of about 43. Even though the results for Lusitano indicate a strong bottleneck on sire-paths, they are not as severe as observed for the Thoroughbred, where one sire alone contributes with 95\% of the Y-chromosome sources represented (Cunningham et al., 2001). For the founder mt-DNA sources, the 10 most influential mares contribute with $38 \%$ of the current lineages represented in Lusitano and $72 \%$ in the Thoroughbred (Cunningham et al., 2001). Our results indicate that the variability in maternal genetic contributions, which has been reported to be small when the Lusitano horse breed was established (Lopes et al., 2005), has been further reduced over the years, given the genetic bottlenecks which have occurred.

The detrimental effects of inbreeding are well known, and include a decrease in genetic variability in inbred populations and a reduction in performance known as inbreeding depression, which affects mostly fitnessrelated traits (Falconer and MacKay, 1996). In horses, a reduction in genetic variability has been observed in several threatened breeds (Hedrick et al., 1999; Luis et al., 2007a), and evidence of inbreeding depression has been documented for morphological (Gandini et al., 1992; Gomez et al., 2009), reproductive (Gonçalves et al., 2011; Sevinga et al., 2004) and performance (Klemetsdal, 1998) traits.

Taken together, the results of our study indicate that the Lusitano horse breed currently has a mean level of inbreeding above $11 \%$ and an effective population size that has declined steadily over the last decades, reflecting the increase in the rate of inbreeding, which is now about $1.8 \% / g e n e r a t i o n$. These results demonstrate that genetic erosion is occurring in the Lusitano at a considerable rate, and steps to control inbreeding must be undertaken. Notwithstanding, the rate and level of inbreeding have not been as dramatic as they could be, due to the large number of stallions used in reproduction, and because most studs exercise some care in mate allocation. Nowadays, the major concern in managing the genetic diversity of the Lusitano horse breed is the short-term decrease in genetic variability due to the loss of genetic contributions from founders and ancestors, more than the long-term effect of inbreeding itself. Currently, nearly one-third of the genetic pool is contributed by two ancestors, about one-half by two founder studs and almost only two Y chromosome founder lineages are presently represented.

The results of our study reflect the intensive emphasis that has been placed on a few sire-families over the years, and raise concerns regarding the conservation of genetic variability for the future. Methods designed to minimize inbreeding and maximize the maintenance of genetic contributions from different founders and ancestors have been proposed for different livestock species. These include using molecular and pedigree information in selection decisions, maximizing genetic contributions from different ancestors, planning mating decisions, restricting family size, optimizing effective population size and generation intervals, etc. (Alderson, 1992; FAO, 1998; Fernandez et al., 2005, 2008; Meuwissen, 2007; Sonesson et al., 2000; Villanueva et al., 2004; Woolliams, 2007; Weigel, 2001). An appropriate combination of these methodologies should help preventing further losses of genetic variability in the Lusitano horse breed.

\section{Conclusions and implications}

Our study with Lusitano horses indicates that a serious reduction in genetic diversity is taking place in this breed, which is mostly evident from the progressive loss of genetic contributions of founders and ancestors. Changes in selection and mating strategies should be envisaged, with the aim of minimizing inbreeding and insuring that genetic contributions from different founders and ancestors are balanced, in order to maintain genetic variability for the future.

\section{Conflict of interest statement}

The authors report that there are no conflicts of interest relevant to this publication.

\section{Acknowledgments}

The authors wish to express thanks to Fundação Alter Real and Associação Portuguesa de Criadores do Cavalo Puro-Sangue Lusitano (APSL) for providing the data used in this study. Two anonymous referees are thanked for useful comments and suggestions.

\section{References}

Alderson, L., 1992. A system to maximize the maintenance of genetic variability in small populations. In: Alderson, L., Bodo, I. (Eds.), Genetic Conservation of Domestic Livestock No. II, CABI, Wallingford, UK, pp. 18-29.

APSL, 2010. Studbook Regulation. Associação Portuguesa de Criadores do Cavalo Puro-sangue Lusitano. Cascais, Portugal.

Azor, P.J., 2009. Horse Biodiversity and their Contribution to Rural Development in Spain. EAAP. 60th Annual Meeting, Barcelona, Spain.

Boichard, D., Maignel, L., Verrier, E., 1997. The value of using probabilities of gene origin to measure genetic variability in a population. Genet. Sel. Evol. 29, 5-23.

Bowling, A.T., Ruvinsky, A., 2000. Genetic aspects of domestication, breeds and their origins. In: Bowling, A.T., Ruvinsky, A. (Eds.), The Genetics of the Horse, CABI Publishing, Oxon, UK, pp. 25-52.

Caballero, A., Toro, M.A., 2000. Interrelations between effective population size and other pedigree tools for the management of conserved populations. Genet. Res. 75, 331-343.

Carolino, N., Gama, L., 2008. Indicators of genetic erosion in an endangered population: the Alentejana cattle breed in Portugal. J. Anim. Sci. 86, 47-56.

Cervantes, I., Molina, A., Goyache, F., Gutierrez, J.P., Valera, M., 2008. Population history and genetic variability in the Spanish Arab horse assessed via pedigree analysis. Livest. Sci. 113, 24-33.

Cervantes, I., Gutiérrez, J.P., Molina, A., Goyache, F., Valera, M., 2009. Genealogical analyses in open populations: the case of three Arabderived Spanish horse breeds. J. Anim. Breed. Genet. 126, 335-347.

Costa, M.D., Bergmann, J.A.G., Resende, A.S.C., Fonseca, C.G., 2005. Análise temporal da endogamia e do tamanho efetivo da populaç ão de equinos da raça Mangalarga Marchador. Arq. Bras. Med. Vet. Zootec. 57, 112-119.

Cunningham, E., Dooley, J., Splan, R., Bradley, D., 2001. Microsatellite diversity, pedigree relatedness and the contributions of founder lineages to thoroughbred horses. Anim. Genet. 32, 360-364. 
Curik, I., Zechner, P., Sölkner, J., Achmann, R., Bodo, I., Dovc, P., Kavar, T., Marti, E., Brem, G., 2003. Inbreeding, microsatellite heterozygosity, and morphological traits in Lipizzan horses. J. Hered. 94 (2), 125-132.

Druml, T., Baumung, R., Solkner, J., 2009. Pedigree analysis in the Austrian Noriker draught horse: genetic diversity and the impact of breeding for coat colour on population structure. J. Anim. Breed. Genet. 126, 348-356.

Falconer, D.S., MacKay, T.F.C., 1996. Introduction to Quantitative Genetics, 4th ed. Longmans Green, Essex, UK.

FAO, 1998. Secondary Guidelines for Development of National Farm Animal Genetic Resources Management Plans: Management of Small Populations at Risk. FAO, Rome, Italy.

Fernandez, J., Villanueva, B., Pong-Wong, R., Toro, M., 2005. Efficiency of the use of pedigree and molecular marker information in conservation programs. Genetics 170,1313-1321.

Fernandez, J., Toro, M., Caballero, A., 2008. Management of subdivided populations in conservation programs: development of a novel dynamic system. Genetics 179 (1), 683-692.

Gandini, G.C., Bagnato, A., Miglior, F., Pagnacco, G., 1992. Inbreeding in the Italian Haflinger horse. J. Anim. Breed. Genet. 109, 433-443.

Goddard, M.G., Smith, C., 1990. Optimum number of bull sires in dairycattle breeding. J. Dairy Sci. 73, 1113-1122.

Gomez, M., Valera, M., Molina, A., Gutierrez, J.P., Goyache, F., 2009. Assessment of inbreeding depression for body measurements in Spanish Purebred (Andalusian) horses. Livest. Sci. 122, 149-155.

Gonçalves, R.W., Costa, M.D., Rocha Junior, V.R., Costa, M.R., Silva, E.S.P., Ribeiro Filha, A.M., 2011. Efeito da endogamia sobre características reprodutivas em um rebanho da raça Mangalarga Marchador. Rev. Bras. Saúde Prod. Anim. 12, 641-649.

Gutierrez, J.P., Goyache, F., 2005. A note on ENDOG: a computer program for analysing pedigree information. J. Anim. Breed. Genet. 122, 172-176.

Gutierrez, J.P., Cervantes, I., Goyache, F., 2009. Improving the estimation of realized effective population sizes in farm animals. J. Anim. Breed. Genet. 126, 327-332.

Hamann, H., Distl, O., 2008. Genetic variability in Hanoverian warmblood horses using pedigree analysis. J. Anim. Sci. 86, 1503-1513.

Hedrick, P., Parker, K., Miller, E., Miller, P., 1999. Major histocompatibility complex variation in the endangered Przewalski's horse. Genetics $152(4), 1701-1710$.

Hill, W., 2000. Maintenance of quantitative genetic variation in animal breeding programmes. Livest. Prod. Sci. 63, 99-109.

James, J., 1972. Computation of genetic contributions from pedigrees. Theor. Appl. Genet. 42, 272-273.

Klemetsdal, G., 1998. The effect of inbreeding on racing performance in Norwegian cold-blooded trotters. Genet. Sel. Evol. 30 (4), 351-366.

Lacy, R., 1989. Analysis of founder representation in pedigrees: founder equivalents and founder genome equivalents. Zoo Biol. 8, 111-123.

Loch, S., 1986. The Royal Horse of Europe: The Story of the Andalusian and Lusitano. JA Allen \& Co Ltd., UK.

Lopes, M.S., Mendonça, D., Cymbron, T., Valera, M., Costa-Ferreira, J., Câmara Machado, A., 2005. The Lusitano horse maternal lineage based on mitochondrial D-loop sequence variation. Anim. Genet. 36, 196-202.

Luis, C., Cothran, E., Oom, M., 2007a. Inbreeding and genetic structure in the endangered sorraia horse breed: implications for its conservation and management. J. Hered. 98, 232-237.

Luis, C., Juras, R., Oom, M., Cothran, E., 2007b. Genetic diversity and relationships of Portuguese and other horse breeds based on protein and microsatellite loci variation. Anim. Genet. 38, 20-27.

MacCluer, J.W., Boyce, A.J., Dyke, B., Weitkamp, L.R., Pfenning, D.W., Parsons, C.J., 1983. Inbreeding and pedigree structure in Standarbred horses. J. Hered. 74, 394-399.

MAPA, 2003. Esquema de seleccíon del caballo de Pura Raza Española. Ed. Ministério de Agricultura, Pesca y Alimentacíon. Secretaria General de Agricultura y Alimentacíon. Direccion General de Ganaderia.
McPhee, H., Wright, S., 1925. Mendelian analysis of the pure breeds of livestock III. The Shorthorns J. Hered. 16 (6), 205-215.

Meuwissen, T.H.E., Woolliams, J.A., 1994. Effective sizes of livestock populations to prevent a decline in fitness. Theor. Appl. Genet. 89, $1019-1026$.

Meuwissen, T.H.E., 2007. Operation of conservation schemes. In: Oldenbroek, J.K. (Ed.), Utilisation and Conservation of Farm Animal Genetic Resources, Wageningen Academic Publishers, The Netherlands, pp. 167-193.

Mota, M.D.S., Almeida Prado, R.S., Sobreiro, J., 2006. Characterization of the Mangalarga horse population in Brazil. Arch. Zootec. 55, 31-37.

Moureaux, S., Verrier, E., Ricard, A., Meriaux, J., 1996. Genetic variability within French race and riding horse breeds from genealogical data and blood marker polymorphisms. Genet. Sel. Evol. 28 (1), 83-102.

Poncet, P., Pfister, W., Muntwyler, J., Glowatzki-Mullis, M., Gaillard, C. 2006. Analysis of pedigree and conformation data to explain genetic variability of the horse breed Franches-Montagnes. J. Anim. Breed. Genet. 123, 114-121.

Ricard, A., Brums, E., Cunningham, E.P., 2000. Genetics of performance traits. In: Bowling, A.T., Ruvinsky, A. (Eds.), The Genetics of the Horse, CABI Publishing, UK, pp. 411-438.

Robertson, A., 1953. A numerical description of breed structure. J. Agric. Sci. 43, 334-336

Royo, L.J., Alvarez, I., Gutierrez, J.P., Fernandez, I., Goyache, F., 2007. Genetic variability in the endangered Asturcon pony assessed using genealogical and molecular information. Livest. Sci. 107, 162-169.

SAS Institute, 2004. SAS ${ }^{\mathbb{1}}$ 9.1.2 for Microsoft Windows. SAS International, Heidelberg, Germany.

Sevinga, M., Vrijenhoek, T., Hesselink, J., Barkema, H., Groen, A., 2004. Effect of inbreeding on the incidence of retained placenta in Friesian horses. J. Anim. Sci. 82, 982-986.

Sonesson, A., Grundy, B., Woolliams, J., Meuwissen, T., 2000. Selection with control of inbreeding in populations with overlapping generations: a comparison of methods. Anim. Sci. 70, 1-8.

Sorensen, A., Sorensen, M., Berg, P., 2005. Inbreeding in Danish dairy cattle breeds. J. Dairy Sci. 88, 1865-1872.

Teegen, R., Edel, C., Thaller, G., 2009. Population structure of the Trakehner Horse breed. Animal 3, 6-15.

Tunnell, J., Sanders, J., Williams, J., Potter, G., 1983. Pedigree analysis of 4 decades of Quarter Horse breeding. J. Anim. Sci. 57, 585-593.

Valera, M., Molina, A., Gutierrez, J.P., Gomez, J., Goyache, F., 2005. Pedigree analysis in the Andalusian horse: population structure, genetic variability and influence of the Carthusian strain. Livest Prod. Sci. 95, 57-66.

Van Vleck, L.D., 1993. Selection Index and Introduction to Mixed Model Methods. CRC Press, Boca Raton, FL.

Vicente, A.A., Carolino, N., Gama, L.T., 2009. Demographic parameters in Lusitano horse. Arch. Zootec. 58 (Suppl. 1), 501-504.

Villanueva, B., Pong-Wong, J.A., Woolliams, J.A., Avendaño, S., 2004 Managing genetic resources in selected and conserved populations. In: Simm, G., Villanueva, B., Sinclair, K.D., Townsend, S. (Eds.), Farm Animal Genetic Resources, Nottingham University Press, Nottingham, UK, pp. 113-131.

Weigel, K.A., 2001. Controlling inbreeding in modern breeding programs. J. Dairy Sci. 84 (Suppl. E), E177-E184.

Woolliams, J., 2007. Genetic contributions and inbreeding. In: Oldenbroek, J.K. (Ed.), Utilisation and Conservation of Farm Animal Genetic Resources, Wageningen Academic Publishers, Wageningen, The Netherlands, pp. 147-166.

Zechner, P., Sölkner, J., Bodo, I., Druml, T., Baumung, R., Achmann, R. Marti, E., Habe, F., Brem, G., 2002. Analysis of diversity and population structure in the Lipizzan horse breed based on pedigree information. Livest. Prod. Sci. 77, 137-146. 